\section{Commentary: Coronary revascularization: How should we do it?}

\author{
Alex Sotolongo, MD, and Arnar Geirsson, MD
}

In their report, Torregrossa and colleagues ${ }^{1}$ have demonstrated a technique for performing robotically sutured coronary anastomosis on a beating heart using the da Vinci $\mathrm{Si}$ system (Intuitive Surgical, Sunnyvale, Calif). The authors have presented an intraoperative film depicting a mature and robust method for performing a sutured anastomosis on a beating heart. The unparalleled visualization afforded by the da Vinci system and the precision and dexterity of the endoscopic wristed articulation are on full display in their demonstration of a robotically performed left internal mammary artery-left anterior descending artery anastomosis. The technical advantages of this platform are expertly presented and will be sure to capture the imagination of coronary surgeons unfamiliar with robotic cardiac surgery.

During the past 2 decades, robotics have entered the mainstream of interventional coronary care, with applications ranging from robotic-assisted percutaneous coronary intervention $^{2}$ to robotic coronary artery bypass. In the surgical realm, totally endoscopic coronary artery bypass has produced results that are in line with traditional techniques ${ }^{3}$ over nearly 20 years of observation. Despite the encouraging reported outcomes, adoption of endoscopic coronary surgery within the US cardiac surgical community has been low. ${ }^{4}$ This can be attributable to the steep learning curve, ${ }^{5}$ increased hospital costs, ${ }^{6}$ and lack of high-quality evidence of its safety and efficacy compared with traditional techniques.

The barriers to entry for robotic cardiac surgery remain formidable, as do the technical limitations associated with the technique. However, it is likely that a small and highly

\footnotetext{
From the Section of Cardiac Surgery, Department of Surgery, Yale-New Haven Health, New Haven, Conn.

Disclosures: The authors reported no conflicts of interest.

The Journal policy requires editors and reviewers to disclose conflicts of interest and to decline handling or reviewing manuscripts for which they may have a conflict of interest. The editors and reviewers of this article have no conflicts of interest.

Received for publication June 11, 2020; revisions received June 11, 2020; accepted for publication June 17, 2020; available ahead of print June 23, 2020

Address for reprints: Arnar Geirsson, MD, Section of Cardiac Surgery, Department of Surgery, Yale School of Medicine, 333 Cedar St, BB 204, New Haven, CT 06520 (E-mail: Arnar.Geirsson@yale.edu).

JTCVS Techniques 2020;3:173

2666-2507

Published by Elsevier Inc. on behalf of The American Association for Thoracic Surgery. This is an open access article under the CC BY-NC-ND license (http:// creativecommons.org/licenses/by-nc-nd/4.0/).

https://doi.org/10.1016/j.xjtc.2020.06.030
}

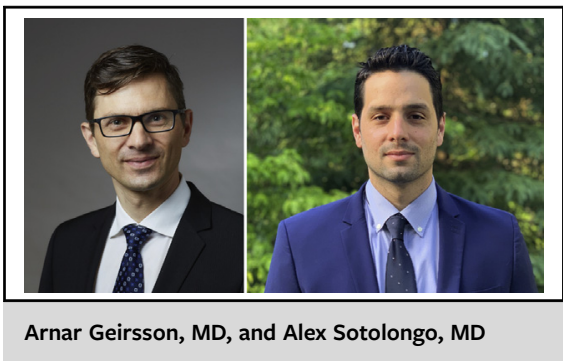

CENTRAL MESSAGE

University of Chicago surgeons demonstrate an elegant and robust method for roboticassisted coronary anastomosis.

selected subset of patients will derive significant benefit from minimally invasive coronary revascularization. Furthermore, given the steep growth in the number of successful applications of robotics in cardiac and thoracic surgery, it is conceivable that robotic surgery could soon supplant open and thoracoscopic techniques as the standard of care. As the debate over the appropriate use of robotics in coronary surgery continues, the authors have provided a compelling argument for an expanded role of totally endoscopic revascularization in the modern surgeon's repertoire. ${ }^{1}$

\section{References}

1. Torregrossa G, Amabile A, Balkhy HH. Totally robotic sutured coronary artery bypass grafting: how we do it. J Thorac Cardiovasc Surg Tech. 2020;3:170-2.

2. Granada JF, Delgado JA, Uribe MP, Fernandez A, Blanco G, Leon MB, et al. Firstin-human evaluation of a novel robotic-assisted coronary angioplasty system. JACC Cardiovasc Interv. 2011;4:460-5.

3. Göbölös L, Ramahi J, Obeso A, Bartel T, Hogan M, Traina M, et al. Robotic totally endoscopic coronary artery bypass grafting: systematic review of clinical outcomes from the past two decades. Innov Technol Tech Cardiothorac Vasc Surg. 2019;14:5-16.

4. Whellan DJ, McCarey MM, Taylor BS, Rosengart TK, Wallace AS, Shroyer ALW, et al. Trends in robotic-assisted coronary artery bypass grafts: a study of the Society of Thoracic Surgeons adult cardiac surgery database, 2006 to 2012. Ann Thorac Surg. 2016;102:140-6.

5. Cheng N, Gao C, Yang M, Wu Y, Wang G, Xiao C. Analysis of the learning curve for beating heart, totally endoscopic, coronary artery bypass grafting. J Thorac Cardiovasc Surg. 2014;148:1832-6.

6. Pasrija C, Kon ZN, Ghoreishi M, Lehr EJ, Gammie JS, Griffith BP, et al. Cost and outcome of minimally invasive techniques for coronary surgery using robotic technology. Innov Technol Tech Cardiothorac Vasc Surg. 2018;13:282-6. 